Tropical Journal of Pharmaceutical Research December 2015; 14 (12): 2299-2305

ISSN: 1596-5996 (print); 1596-9827 (electronic)

(1) Pharmacotherapy Group, Faculty of Pharmacy, University of Benin, Benin City, 300001 Nigeria.

All rights reserved.

Available online at http://www.tjpr.org

Original Research Article

http://dx.doi.org/10.4314/tjpr.v14i12.21

\title{
Deworming Campaign in Eastern Afghanistan - Prevalence of Intestinal Parasites and Adoption of Treatment Strategy
}

\author{
Krzysztof Korzeniewski ${ }^{1 *}$, Alina Augustynowicz ${ }^{1}$ and Anna Lass ${ }^{2}$ \\ ${ }^{1}$ Department of Epidemiology and Tropical Medicine, Military Institute of Medicine, Gdynia, ${ }^{2}$ Department of Tropical \\ Parasitology, Medical University of Gdańsk, Poland \\ *For correspondence: Email: kktropmed@wp.pl; Tel: +48 665707396
}

Received: 19 April 2015

Revised accepted: 13 November 2015

\begin{abstract}
Purpose: To estimate the prevalence and species of intestinal parasites in an Afghan community as well as to establish appropriate treatment method for each of the detected pathogens.

Methods: Parasitological examination of stool samples collected from 777 children aged 1-17 years, treated in Ghazni Provincial Hospital (eastern Afghanistan) conducted in the period 2012 - 2013 made it possible to implement dedicated antiparasitic treatment.

Results: Of 312 children (40.2\% of the examined group; $p<0.05)$ infected with nematodes $(n=154$, $19.7 \%)$, cestodes $(n=90,11.6 \%)$, trematodes $(n=16,2.1 \%)$, and protozoa $(n=135,17.4 \%), 67$ were diagnosed with co-infections (mainly ascariasis + giardiasis, ascariasis + hymenolepiasis, giardiasis + hymenolepiasis, ascariasis + giardiasis + hymenolepiasis) and received complex therapy (albendazole + metronidazole, albendazole + praziquantel, metronidazole + praziquantel, and albendazole + metronidazole + praziquantel).

Conclusion: Owing to high prevalence of multiple co-infections among inhabitants of the Afghan community, it seems that a mass deworming campaign with a single-dose chemotherapy (albendazole $400 \mathrm{mg}$ or mebendazole $500 \mathrm{mg}$ ) may prove ineffective in eradicating intestinal parasites in the local population.
\end{abstract}

Keywords: Afghanistan, Intestinal parasites, Hymenolepiasis, Ascariasis, Giardiasis, Metronidazole, Albendazole, Praziquantel, Mebendazole, Deworming

Tropical Journal of Pharmaceutical Research is indexed by Science Citation Index (SciSearch), Scopus, International Pharmaceutical Abstract, Chemical Abstracts, Embase, Index Copernicus, EBSCO, African Index Medicus, JournalSeek, Journal Citation Reports/Science Edition, Directory of Open Access Journals (DOAJ), African Journal Online, Bioline International, Open-J-Gate and Pharmacy Abstracts

\section{INTRODUCTION}

The incidence of gastrointestinal infectious and invasive diseases in Afghanistan is exceptionally high, which is mainly influenced by soil and water contamination [1], a limited number of households obtaining drinking water from controlled sources and having improved sanitation facilities, a large number of asymptomatic carriers of contagious and parasitic diseases, and mass migration [2]. Owing to limited diagnostic capabilities of the Afghan health care, reports on the prevalence of diseases in the general population are rarely laboratory-confirmed. An improvement in the health status of the Afghan population is additionally restrained by poor public awareness of the principles of hygiene and disease prevention [3].

It is estimated that the rates of bacterial and viral diarrheal illnesses as well as the prevalence of intestinal parasitic infections are high among inhabitants of Afghanistan. According to the U.S. Department of Defense, the rates of amebiasis in the general population reach $3 \%$, giardiasis has 
been found in nearly $11 \%$ of the surveyed children, and as much as $90 \%$ of the population may be infected with at least one intestinal parasite [4]. The data, however, are only rough estimates based on the results of a few screening studies.

The purpose of this study was to estimate the prevalence and species of intestinal parasites in the Afghan community as well as to establish appropriate treatment method for each of the detected pathogens.

\section{EXPERIMENTAL}

\section{Study population}

Polish medical personnel serving in the International Security Assistance Force Operation in Afghanistan in cooperation with the Head of the Health Service Department in Ghazni Province Zia Ghul, MD and the Head of Ghazni Provincial Hospital (GPH) Baz Mohammat Hemmat, MD, surveyed 777 Afghan children aged 1-17 years, who were treated for internal complaints in Ghazni Provincial Hospital (eastern Afghanistan) from March 2012 to March 2013.

\section{Sample collection}

Three stool samples were collected from each patient (every second day), the samples were fixed in $10 \%$ formalin, and transported to the Military Institute of Medicine in Poland, where they were tested by light microscopy using the methods of direct smear and decantation, both counterstained with Lugol's solution as well as Fülleborn's flotation technique. Each of the samples collected from every patient was tested by means of all three methods. Thus, a total of 6993 parasitological tests were performed.

\section{Laboratory procedures}

The diagnosis of intestinal parasites was performed by light microscopy using three stooltesting methods [5] as follows:

\section{Direct smear in Lugol's solution}

Approximately $2 \mathrm{mg}$ of stool specimen was collected with a glass rod and applied onto a slide, a drop of Lugol's solution was added and the material was smeared over a $4 \mathrm{~cm}^{2}$ surface. Next, a cover slide was placed on top of the preparation and the material was examined microscopically under x20 magnification.
Preparation from decantation in distilled water

Approximately $2 \mathrm{ml}$ of stool specimen was mixed thoroughly with a small amount of water in a test tube. Next, water was added to the top of the tube and mixed again. After $30 \mathrm{~min}$ the supernatant was decanted and another portion of water was added. The procedure was repeated until clear supernatant was obtained, generally three to four times. The sediment was then placed on a slide and stained with Lugol's solution for microscopic examination at $\times 40$ magnification).

\section{Preparation from Fülleborn's flotation}

Approximately $2 \mathrm{ml}$ of stool specimen was mixed with saturated sodium chloride, $\mathrm{NaCl}$ solution in a test tube. Next, the $\mathrm{NaCl}$ solution was added to the top of the tube. A cover slide was placed gently on top of the tube and in contact with the suspension. After 30 minutes, the cover slide was gently removed with tweezers and placed the wet side down on a slide. The preparation was ready for microscopic examination (x10 magnification).

\section{Statistical analysis}

Statistical analysis was performed using STATISTICA (data analysis software system) version 10.0 (SN JGNP3087539302AR-E) and Microsoft Excel 2010. The quantitative variables were characterized by the arithmetic mean of standard deviation or median or max/min (range) and $95 \%$ confidence interval. The qualitative variables were presented with the use of count and percentage. Statistical significance of differences between two groups (unpaired variables model) was processed with the $\mathrm{t}$ Student test (or Welch test in the case of lack of homogeneity) or Mann-Withney $U$ test (in cases where conditions of performing the t-Student test were not satisfied or for variables measured by ordinal scale). Chi-squared tests for independence were used for qualitative variables. In order to determine dependence, strength and direction between variables, correlation analysis was used by determining the Pearson or Spearman's correlation coefficients. In all the calculations the statistical significance level of $p \leq 0.05$ was used.

\section{RESULTS}

The mean age in the study population of 777 Afghan children treated in Ghazni Provincial Hospital was 8.7 years (range 1-17). The mean age of females was 8.7 and males 9.0 (range 1- 
17). The analysis of age and sex did not show statistically significant differences (Mann-Whitney $U$ test $1.28, p=0.2018$ ). The mean age of children without infections was 8.7 and children with infections was 9.2 (range 1-17). The analysis of age and infection rates did not show statistically significant differences (Mann-Whitney $U$ test $1.43, p=0.1533$ ). There were 296 (38.1 $\%)$ females and $481(61.9 \%)$ males in the study group. Infections were confirmed in 312 children $(40.2 \%)-106$ females $(34.0 \%)$ and 206 males $(66.0 \%)$.

Parasitological examination, which revealed that $40.2 \%$ of the children treated in GPH in eastern Afghanistan were infected with pathogenic intestinal parasites, and another $35.0 \%$ with non-pathogenic protozoa [6], helped implement appropriate treatment in line with current standards of the antiparasitic therapy [7]. Of the 312 children infected with nematodes $(154,19.7$ $\%)$, cestodes $(90,11.6 \%)$, trematodes $(16,2.1$
$\%)$, and protozoa (135, $17.4 \%), 67$ were diagnosed with co-infections (mainly ascariasis + giardiasis; ascariasis + hymenolepiasis; giardiasis + hymenolepiasis; ascariasis + giardiasis + hymenolepiasis) and received complex therapy (albendazole + metronidazole; albendazole + praziquantel; metronidazole + praziquantel; albendazole + metronidazole + praziquantel) (Table 1).

There were some statistically significant differences in the distribution of the types of intestinal parasites among the infected children $(p<0.001)$. The most common species were nematodes and protozoa (see Table 1).

The percentage of infections among males was significantly higher than among infected females $(p=0.0324)$. The analysis of the rates of infections with intestinal parasites among children by sex did not show any statistically significant differences (Figure 1).

Table 1: Intestinal parasites in Afghan children treated in Ghazni Provincial Hospital, 2012-2013

\begin{tabular}{|c|c|c|c|c|c|}
\hline Intestinal parasites & $\begin{array}{c}\text { Number } \\
\text { of infections } \\
(n=395)\end{array}$ & $\begin{array}{c}\% \text { Infected } \\
\text { children( } \mathrm{n}= \\
312)\end{array}$ & $\begin{array}{l}\% \text { Tested } \\
\text { children } \\
(n=777)\end{array}$ & $P$-value & Treatment \\
\hline Nematodes & 154 & 49.4 & 19.7 & $\mathrm{p}<0.001$ & \\
\hline Ascarislumbricoides & 134 & 42.9 & 17.2 & $\mathrm{p}<0.001$ & Albendazole \\
\hline Enterobiusvermicularis & 17 & 5.4 & 2.2 & $p=0.001$ & Albendazole \\
\hline Strongyloidesstercoralis & 2 & 0.6 & 0.3 & $p=0.001$ & Albendazole \\
\hline $\begin{array}{l}\text { Ancylostomaduodenale/ } \\
\text { Necatoramericanus }\end{array}$ & 1 & 0.3 & 0.1 & $p=0.001$ & Albendazole \\
\hline Cestodes & 90 & 28.8 & 11.6 & $p=0.001$ & \\
\hline Hymenolepis nana & 64 & 20.5 & 8.2 & $p=0.001$ & Praziquantel \\
\hline Hymenolepisdiminuta & 20 & 6.4 & 2.6 & $p=0.001$ & Praziquantel \\
\hline Taenia spp. & 6 & 1.9 & 0.8 & $p=0.001$ & Praziquantel \\
\hline Trematodes & 16 & 5.1 & 2.1 & $p=0.001$ & \\
\hline Dicrocoeliumdendriticum & 11 & 3.5 & 1.4 & $p=0.001$ & Praziquantel \\
\hline Fasciola hepatica & 5 & 1.6 & 0.6 & $p=0.001$ & Triclabendazole \\
\hline Protozoa & 135 & 43.3 & 17.4 & $\mathrm{p}<0.001$ & \\
\hline Giardia intestinalis & 130 & 41.7 & 16.7 & $p<0.001$ & Metronidazole \\
\hline Entamoeba histolytica & 5 & 1.6 & 0.6 & $p=0.001$ & Metronidazole \\
\hline Total & 312 & 100.0 & 40.2 & $p<0.001$ & \\
\hline
\end{tabular}

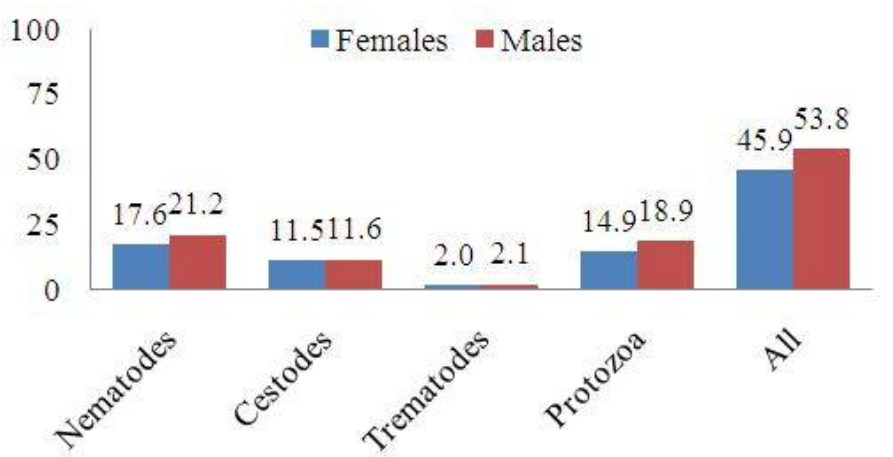

Figure 1: Distribution of parasitic infections in Afghan children by sex 
Table 2: Distribution of parasitic infections among Afghan children by age

\begin{tabular}{lccccc}
\hline $\begin{array}{l}\text { Age } \\
\text { (years) }\end{array}$ & $\begin{array}{c}\text { Nematodes } \\
(\mathbf{n}=\mathbf{1 5 4 )}\end{array}$ & $\begin{array}{c}\text { Cestodes}(\mathbf{n}=\mathbf{9} \\
\mathbf{0})\end{array}$ & $\begin{array}{c}\text { Trematodes } \\
(\mathbf{n}=\mathbf{1 6})\end{array}$ & $\begin{array}{c}\text { Protozoa } \\
(\mathbf{n}=\mathbf{1 3 5})\end{array}$ & $\begin{array}{c}\text { Total } \\
(\mathbf{n}=\mathbf{3 9 5})\end{array}$ \\
\hline 1 & $4(2.6)$ & $3(3.3)$ & $0(0.0)$ & $2(1.5)$ & $9(2.3)$ \\
2 & $1(0.6)$ & $0(0.0)$ & $0(0.0)$ & $2(1.5)$ & $3(0.8)$ \\
3 & $3(1.9)$ & $4(4.4)$ & $1(6.3)$ & $6(4.4)$ & $14(3.5)$ \\
4 & $4(2.6)$ & $7(7.8)$ & $0(0.0)$ & $10(7.4)$ & $21(5.3)$ \\
5 & $6(3.9)$ & $5(5.6)$ & $0(0.0)$ & $7(5.2)$ & $18(4.6)$ \\
6 & $10(6.5)$ & $7(7.8)$ & $0(0.0)$ & $10(7.4)$ & $27(6.8)$ \\
7 & $8(5.2)$ & $5(5.6)$ & $2(12.5)$ & $11(8.1)$ & $26(6.6)$ \\
8 & $15(9.7)$ & $9(10.0)$ & $3(18.8)$ & $19(14.1)$ & $46(11.6)$ \\
9 & $16(10.4)$ & $8(8.9)$ & $3(18.8)$ & $11(8.1)$ & $38(9.6)$ \\
10 & $20(13.0)$ & $10(11.1)$ & $3(18.8)$ & $14(10.4)$ & $47(11.9)$ \\
11 & $17(11.0)$ & $5(5.6)$ & $1(6.3)$ & $8(5.9)$ & $31(7.8)$ \\
12 & $15(9.7)$ & $7(7.8)$ & $1(6.3)$ & $12(8.9)$ & $35(8.9)$ \\
13 & $10(6.5)$ & $4(4.4)$ & $1(6.3)$ & $7(5.2)$ & $22(5.6)$ \\
14 & $9(5.8)$ & $8(8.9)$ & $1(6.3)$ & $7(5.2)$ & $25(6.3)$ \\
15 & $8(5.2)$ & $3(3.3)$ & $0(0.0)$ & $3(2.2)$ & $14(3.5)$ \\
16 & $4(2.6)$ & $3(3.3)$ & $0(0.0)$ & $5(3.7)$ & $12(3.0)$ \\
17 & $4(2.6)$ & $2(2.2)$ & $0(0.0)$ & $1(0.7)$ & $7(1.8)$ \\
\hline
\end{tabular}

Detailed information on the numbers and rates of intestinal parasites by age of the infected children is presented in Table 2. The analysis of the distribution of parasitic infections among Afghan children by age did not show any statistically significant differences $\left(\mathrm{Chi}^{2}\right.$ test 29.97, $p=0.9807$ ).

The analysis of the distribution of parasitic infections among males did not show statistically significant differences (Chi ${ }^{2}$ test 39.97, $p=$ $0.7885)$, the same applied to infected females (Chi ${ }^{2}$ test $48.15, p=0.4666$ ).

The analysis of the relationship between age and number of infections among children did not show statistically significant differences, both in males $(R=0.26, p=0.3070)$ and females $(R=$ $0.24, p=0.3530)$.

The relationship between children's age/sex and the rates of parasitic infections was also examined. The results of univariate and multivariate regression did not show statistically significant relationship between age, sex and infection effect among infected children.

\section{DISCUSSION}

The Afghan community, living in poor socioeconomic conditions and having a limited access to health care, is an example of a population characterized by a high rate of parasitic infections. In February and March 2003, the United Nations World Food Programme (WFP), in cooperation with the World Health Organization (WHO) and the Afghan Ministries of Health and of Education, conducted a crosssectional parasitological examination in a group of 1001 children aged 8-15 from four Afghan provinces (Kabul, Nangarhar, Farah, Kandahar). The survey revealed the presence of intestinal parasites in $47.2 \%$ of the examined children. The most common pathogen was Ascaris lumbricoides, detected in $40.9 \%$ of the population under study. The authors of the survey suggested that regular administration of single-dose chemotherapy (albendazole $400 \mathrm{mg}$ or mebendazole $500 \mathrm{mg}$ ) would be a costeffective method of controlling soil-transmitted helminth infections at the public health level [8]. In September 2004, WFP announced that the deworming campaign which had started six months before involved more than 4.5 million school children aged 6-12 living in Afghanistan. The children were given a single oral dose of mebendazole. The total cost of deworming was approximately US $\$ 0.10$ per child [9]. WHO recommends annual mass antihelminthic treatment of all school-age children in areas where the prevalence is $>20 \%$ or twice a year when the prevalence is $>50 \%$, with the goal of preventing adverse effects on nutritional status, hemoglobin concentration and cognition in order to improve health, intellect and school attendance [10]. Improvements in sanitation and health education are also important interventions required in order to change practices and behaviors that reduce the transmission of intestinal parasites [11,12].

Preventive chemotherapy represents a powerful but short-term control strategy for parasitic infections of the gastrointestinal tract. Since humans are often re-infected rapidly, long-term solutions require improvements in water, sanitation, and hygiene (WASH). WASH interventions are diverse, potentially including improvements in water access (e.g., water 
quality, water quantity, and distance to water), sanitation access (e.g., access to improved latrines, latrine maintenance, and fecal sludge management), and hygiene practices (e.g., handwashing before eating and after defecation, water treatment, soap use, wearing shoes, and water storage practices) [13].

Most mass deworming programs have been school-based because children tend to have the highest prevalence and intensity of infection [14]. The programs focus on geographic areas with a high prevalence, using drugs recommended by the WHO [15]. Effective chemotherapy includes mainly the use of mebendazole or albendazole, and occasionally pyrantel pamoate or levamisole in the intestinal nematode treatment [16]. However, the large-scale administration of antihelminthics might result in the development and spread of drug resistant nematodes [17], which is already a significant problem in veterinary medicine [18]. Selected studies pointed, that the administration of a single dose of mebendazole lacked efficacy against hookworm infections among schoolchildren in Zanzibar [19] and Vietnam [20]. Keiser and Utzinger [17] reported high cure rates of single dose mebendazole and albendazole for Ascaris lumbricoides (90\%) and low cure rates in the same dose of mebendazole for Trichuris trichiura (36\%) and hookworm (15\%). In Rwanda, a national survey among more than 8000 schoolchildren in 30 districts found an overall soil transmitted helminths prevalence of $66 \%$. A repeat survey conducted one year after the standard deworming found a reduction in ascariasis and trichuriasis prevalence by $14 \%$, and increase in hookworm prevalence by $72 \%$ [21].

The central element in the global strategy of intestinal parasites control is preventive, repeated chemotherapy. Regular treatment aims at reducing the parasites burden below threshold associated with morbidity. The successful efforts to reduce morbidity in local population needed to be supplemented by more integrated and multisectoral approach to public health [16]. This human development agenda was the prime motivation for the highly successful national deworming program in South Korea. National surveys on the prevalence of intestinal parasitic infections in the Korean population have been carried out every 5-7 years since 1971 in order to establish control measures. The first survey conducted in 1971, showed an overall helminth egg positive rate of $84.3 \%$ among Korean people. During the subsequent 30 years, Korea showed very high economic growth with a dramatic decrease of the helminth egg positive rate down to $2.4 \%$ in 1997 . In particular, $A$. lumbriocoides showed a decrease from $54.9 \%$ in 1971 to $0.06 \%$ in 1997 . Other soil-transmitted helminths also presented decreases in the prevalence down to $0.007 \%$ for hookworms and $0.04 \%$ for $T$. trichiura [22].

World Health Organization gave greater emphasis to deworming in specific age groups, especially pre-school children, school age children, and women of reproductive age, and in 2001 the World Health Assembly declared the goal of ensuring that $75 \%$ of all school age children in endemic areas should receive treatment. Pharmaceutical companies have donated treatment specifically for deworming of school children: with $50 \mathrm{mg}$ mebendazole treatments a year from Johnson \& Johnson in 2007, rising to $200 \mathrm{mg}$ in 2010, and $400 \mathrm{mg}$ treatments of albendazole from GlaxoSmithKline in 2012. These donations have had broad impact, increasing the cost-effectiveness of deworming and heightening the attractiveness of deworming programs within public health systems [16]. The large donation of 600 million doses per year announced in the London Declaration (a declaration on neglected tropical diseases was based in part on a new WHO roadmap in UK in 2012) almost completely covers the estimated 610 million school aged children in need of preventive chemotherapy [23, 24], but it does not cover pre-school children, women of child-bearing age or treatments more than once a year [25].

Unfortunately, deworming campaigns launched in the Third World countries of the Middle East and Central Asia in the last years have not been successful. In 2011, only $0.69 \%$ school age children in the Eastern Mediterranean Region (including Afghanistan) received preventive antiparasitic therapy (albendazole or mebendazole) [26]. One of the main reasons why such campaigns end in failure is unstable geopolitical situation in the region, as is the case with Afghanistan, where humanitarian aid is provided mainly by the international coalition forces stationing in the country since 2001. One of the participants in the International Security Assistance Force operation in Afghanistan was the Polish Military Contingent (PMC), which carried out its mandatory tasks in Ghazni Province in eastern part of the country in the period 2008-2014. One of the components of the PMC was a medical unit whose task was to provide treatment and prophylaxis among the local population. Polish military physicians not only treated war casualties, but also diagnosed and treated infectious and invasive diseases. In March and September 2012, two conferences 
were organized in the Ghazni Governor's office; they were attended by Afghan health care workers and focused on the contemporary epidemiological situation and the prevalence of communicable diseases in Afghanistan, including intestinal parasitic infections. In March 2013, medical personnel from PMC Afghanistan designed and implemented the project Capacity building of health care system in Ghazni Province (financed by the Polish Ministry of National Defence). One of the aims of this project was to purchase thousands of medicine doses (albendazole, metronidazole, praziquantel) for the infected children treated in Ghazni Provincial Hospital (tested in the period March 2012 March 2013), as well as for the infected pupils from the Jahan Malika High School (tested in the period November 2013 - April 2014) [27] in the capital of Ghazni Province. The cost of deworming was about 22 afghani (US\$ 0.35) per child. Given large differences in medicine prices between developing and developed countries (the cost of a single dose of albendazole or metronidazole is over US\$ 5 in Europe and USA), the decision was taken to carry out pharmaceutical tests on the compliance of the medicine samples with the requirements for the products. The samples were tested in the Official Medicines Control Laboratory of the National Medicines Institute in Warsaw, Poland. The investigated parameters of Flagyl (metronidazole) $200 \mathrm{mg}$ and $400 \mathrm{mg}$ tablets (Sanofi-Aventis Pakistan Ltd., Korangi Industrial Area, Karachi), and Zentel (albendazole) $200 \mathrm{mg}$ tablets (GlaxoSmithKline Pakistan Ltd., F/268 S.I.T.E., Karachi) were in compliance with the requirements of the British Pharmacopoeia 2012, the United States Pharmacopeia 36, and the European Pharmacopoeia 8th Edition as regards identification, active ingredient content and chemical purity of the product.

Owing to high prevalence of multiple infections (nematodes, cestodes, trematodes, protozoa) in the Afghan community, it seems that a mass deworming campaign with a single-dose chemotherapy (albendazole $400 \mathrm{mg}$ or mebendazole $500 \mathrm{mg}$ ) may prove ineffective in eradicating intestinal parasites in the local population. The effectiveness of deworming may be enhanced by increasing the dosage of albendazole (400 $\mathrm{mg}$ for three-five days) $[28,29]$ or mebendazole (600 $\mathrm{mg}$ for three days) [30] or usage of complex therapy (albendazole $400 \mathrm{mg}$ one dose, metronidazole $250 \mathrm{mg}$ three times daily for five days, praziquantel $5-25 \mathrm{mg} / \mathrm{kg}$ one dose), which, considering the low cost of the medications, seems an acceptable form of the antiparasitic therapy.

\section{Limitation of the study}

The major limitation of this study is the 2 - 4 week period between the collection of stool samples in Ghazni Provincial Hospital in Afghanistan and the examinationof fixed biological material after its transport to Poland.

\section{CONCLUSION}

Owing to high prevalence of multiple coinfections (ascariasis, giardiasis, hymenolepiasis) among inhabitants of Afghanistan, it seems that a mass deworming campaign aiming at eradicating intestinal parasites in the local population should be enhanced by increasing the dosage of albendazole or mebendazole or usage of complex therapy (albendazole, metronidazole, praziquantel).

\section{ACKNOWLEDGEMENT}

This work was funded by Polish Ministry of Defence and Military Institute of Medicine, Poland. The authors are grateful to Baz Mohammad Hemmat, MD (Head of Ghazni Provincial Hospital, Afghanistan) and Zia Ghul, MD (Head of Department of Health Service in Ghazni Province, Afghanistan) for their excellent technical assistance and supervision in patient recruitment and collection of biological samples.

\section{REFERENCES}

1. Safi Z, Buerkert A. Heavy metal and microbial loads in sewage irrigated vegetables of Kabul, Afghanistan. J Agri Rural Dev Tropics Subtropics 2011; 112: 29-36.

2. Korzeniewski K. Epidemiological situation of Afghanistan. Przegl Epidemiol 2005; 60: 147-157.

3. Korzeniewski K, Augustynowicz A, Lass A. Prevalence of intestinal parasites in Afghan community on the example of patients treated in Ghazni Provincial Hospital. Int Marit Health 2014; 65: 68-72.

4. DoD Deployment Health Clinical Center. Operation Enduring Freedom. Walter Reed National Military Medical Center. Bethesda, USA [cited 2014 Nov 03]. Available

from: http://www.pdhealth.mil/deployments/enduring_freed om/concerns.asp\#intestinal.

5. World Health Organization. Basic laboratory methods in medical parasitology. Geneva 1991.

6. Maftoon S. Polish doctors treating kids with digestive disorders. Pajhwok Afgan News, Sept 10, 2012 [cited 2014 Nov 03]. Available from: http://www.pajhwok.com/en/2012/ 09/10/polishdoctors-treating-kids-digestive-disorders.

7. Kappagoda S, Singh U, Blackburn BG. Antiparasitic Therapy. Mayo Clin Proc 2011; 86: 561-583. 
8. Gabrielli AF, Ramsan M, Naumann C, Tsogzolmaa $D$, Bojang $B$, Khoshal $\mathrm{MH}$, et al. Soil-transmitted helminths and haemoglobin status among Afghan children in World Food Programme assisted schools. J Helminthol 2005; 79: 381-384.

9. Sharpe $W$. Largest de-worming campaign in history happens in Afghanistan. Lancet Infect Dis 2004; 4: 601.

10. Montresor A. World Health Organization. Helminth Control in School-age Children: A Guide for Managers of Control Programmes. 2nd ed. Geneva: World Health Organization 2011: 76.

11. Naumann DN, Lundy J, Burns DS, Bailey MS, Bowley DM. Routine Deworming of Children at Deployed HealthCare Facilities. Pediatr Infect Dis J 2013; 32(9): 931-932.

12. Ziegelbauer K, Speich B, Mäusezahl D, Bos R, Keiser J, Utzinger J. Effect of sanitation on soil-transmitted helminth infection: systematic review and metaanalysis. PLoS Med 2012; 9: e1001162.

13. Strunz EC, Addiss DG, Stocks ME, Odgen S, Utzinger J, Freeman MC. Water, Sanitation, Hygiene, and SoilTransmitted Helminth Infection: A Systematic Review and Meta-Analysis. PLoS Med 2014; 11(3): e1001620.

14. Alemu A, Atnafu A, Addis Z, Shiferaw Y, Teklu $T$, Mathewos $B$, et al. Soil transmitted helminths and Schistosoma mansoni infections among school children in Zarima town, northwest Ethiopia. BMC Infect Dis 2011; 11: 189.

15. Crompton DWT. World Health Organization. Preventive Chemotherapy in Human Helminthiasis: Coordinated Use of Anthelminthic Drugs in Control Interventions: A Manual for Health Professionals and Programme Managers. Geneva: World Health Organization 2006 : 62.

16. Bethony J, Brooker S, Albonico M, Geiger SM, Loukas A, Diemert $D$, et al. Soil-transmitted helminth infections: ascariasis, trichuriasis, and hookworm. Lancet 2006; 367: 1521-1532.

17. Keiser J, Utzinger J. Efficacy of current drugs against soil-transmitted helminth infections: systematic review and meta-analysis. JAMA 2008; 299: 1937-1948.

18. Wolstenholme AJ, Fairweather I, Prichard $R$, von Samson-Himmelstjerna G, Sangster NC. Drug resistance in veterinary helminths. Trends Parasitol 2004; 20: 469-476.

19. Albonico M, Bickle Q, Ramsan M, Montresor A, Savioli L, Taylor M. Efficacy of mebendazole and levamisole alone or in combination against intestinal nematode infections after repeated targeted mebendazole treatment in Zanzibar. Bull World Health Organ 2003; 81(5): 343-352.

20. Flohr C, Tuyen LN, Lewis $S$, et al. Low efficacy of mebendazole against hookworm in Vietnam: two randomized controlled trials. Am J Trop Med Hyg 2007; 76(4): 732-736.

21. Ruxin J, Negin J. Removing the neglect from neglected tropical diseases: the Rwandan experience 20082010. Glob Public Health 2012; 7: 812-822.

22. Kim TS, Cho SH, Huh S, Kong Y, Sohn WM, Hwang SS, et al. A Nationwide Survey on the Prevalence of Intestinal Parasitic Infections in the Republic of Korea, 2004. Koran J Parasitol 2009; 47(1): 37-47.

23. World Health Organization. Accelerating work to overcome the global impact of neglected tropical diseases - A roadmap for implementation. Geneva 2012.

24. World Health Organization. Soil-transmitted helminthiases: estimates of the number of children needing preventive chemotherapy and number treated, 2009. Wkly Epidemiol Rec 2011; 86: 257266.

25. Anderson RM, Truscott JE, Pullan RL, Brooker SJ, Hollingsworth TD. How Effective Is School-Based Deworming for the Community-Wide Control of SoilTransmitted Heliminths? PLoS Negl Trop Dis 2013; 7(2): e2027.

26. World Health Organization. Soil-transmitted helminthiases: number of children treated in 2011. Wkly Epidemiol Rec 2013; 88: 145-152.

27. Korzeniewski K, Augustynowicz A, Smoleń A, Lass A. Epidemiology of intestinal parasitic infections in school children in Ghazni Province, eastern Afghanistan. Pak J Med Sci [in press].

28. Horton J. Albendazole: a review of anthelmintic efficacy and safety in humans. Parasitology 2000; 121 Suppl: S113-132.

29. Penggabean $M$, Norhayati $M$, Oothuman P, Fatmah MM. Efficacy of albendazole in the treatment of Trichuris trichiura and Giardia intestinalis infection in rural Malay communities. Med J Malaysia 1998; 53: 408412.

30. Canete R, Escobedo AA, Almirall P, Gonzalez ME, Brito $K$, Cimerman S. Mebendazole in parasitic infections other than those caused by soil-transmitted helminthes. Trans $R$ Soc Trop Med Hyg 2009; 103: 437-442. 